\title{
Dysregulation of energy homeostasis in mice overexpressing insulin-like growth factor-binding protein 6 in the brain
}

Received: 10 December 2004 / Accepted: 16 January 2005 / Published online: 12 May 2005

C) Springer-Verlag 2005

\begin{abstract}
Aims/hypothesis: IGFs, IGF receptors and IGF binding proteins (IGFBPs) are widely expressed in the central nervous system. To investigate the physiological significance of IGFBP-6 in the brain we established two transgenic mouse lines overexpressing human (h)-IGFBP-6 under the control of glial fibrillary acidic protein promoter. Increasing evidence suggests that insulin/IGF signalling pathways could be implicated in the neuroendocrine regulation of energy homeostasis. We explored the impact of brain IGFBP-6 overexpression on the regulation of food intake and energy balance. Methods: Transgenic mice were fed either a control diet or a high-fat diet for up to 3 months. Glucose and insulin tolerance tests were carried out before and after the diet period. Plasma parameters (insulin, leptin, glucose, NEFAs and triglycerides) were measured, and uncoupling protein 1 (UCP-1) expression was quantified in brown adipose tissue. Oxygen consumption was also measured in both groups. Results: The transgenic mice fed a high-fat diet for 3 months developed obesity, showing increases in plasma leptin, glucose and insulin levels and mild insulin resistance. As compared with wild-type mice, no significant differences were found in the quantity of food intake. However, UCP-1 expression was down-regulated in the brown adipose tissue of the transgenic mice. Conclusions/interpretation: Our results show that brain IGFBP-6 has an impact on the regulation
\end{abstract}

G. Bienvenu $\cdot$ D. Seurin $\cdot$ Y. Le Bouc $\cdot$ S. Babajko National Institute of Health and Medical Research (INSERM) Unit 515, St-Antoine Hospital, University of Paris, Paris, France

P. Even

National Institute of Agronomical Research (INRA), Integrated Research Unit (UMR) 914,

Paris, France

C. Magnan $(\bowtie)$

National Council for Scientific Research (CNRS),

Integrated Research Unit (UMR) 7059, University of Paris 7, Paris cedex 05, France

e-mail: magnan@paris7.jussieu.fr

Tel.: +33-1-44277837

Fax: $+33-1-44277836$ of energy homeostasis. These transgenic h-IGFBP-6 mice may be considered a new tool for studies of the involvement of the brain IGF system in metabolism control and obesity.

Keywords Central nervous system · Insulin-like growth factors - Insulin-like growth factor-binding proteins .

Insulin resistance $\cdot$ Obesity $\cdot$ Uncoupling proteins

Abbreviations BAT: brown adipose tissue - GAPDH: glyceraldehyde-3-phosphate dehydrogenase - GFAP: glial fibrillary acidic protein $\cdot \mathrm{h}$ : human - IGFBP: IGF binding protein - UCP: uncoupling protein

\section{Introduction}

The IGF system includes IGF-I and IGF-II, the type 1 and type 2 IGF receptors, and specific IGF binding proteins (IGFBP-1 to IGFBP-6). IGFs are non-covalently bound to the IGFBPs, a family of high-affinity binding proteins that determine IGF bioavailability [1-3]. The IGFBPs modulate the biological effects of the IGFs by increasing their halflives and regulating the local concentration of (free) IGFs [4-6]. Among the IGFBPs, IGFBP-6 has the highest affinity for IGF-II. Furthermore, the affinity of IGF-II for IGFBP-6 is 100-fold higher than its affinity for the type 1 IGF receptor. As a result, IGFBP-6 can inhibit IGF-II mitogenic effects by sequestration $[7,8]$.

In the central nervous system, the IGF system plays a key role in promoting the survival, proliferation and differentiation of neuronal and non-neuronal cells [9-11]. IGF-II is highly expressed in the cerebellum, hypothalamus and ventricles of the rat brain [12-14] and the human brain [15]. Thus, the IGF-II/IGFBP-6 complex could play a specific role in modulating IGF-II function in the adult brain.

We targeted IGFBP-6 expression in the central nervous system of mice by inserting human (h)-IGFBP-6 cDNA under the control of the glial fibrillary acidic protein (GFAP) promoter, which has been successfully used to 
target various gene products to the central nervous system $[16,17]$. We have previously observed that these IGFBP-6 transgenic mice showed a strong transgene expression in the central nervous system, associated with a $25 \%$ decrease in cerebellum size and a 50\% decrease in cerebellum GFAP expression [18].

Increasing evidence suggests that insulin/IGF signalling pathways are implicated in the neuroendocrine regulation of energy homeostasis $[19,20]$. Impairment of insulin signalling has been found in the hypothalamus of obese Zucker rats [21], and mice with a neuron-specific disruption of the insulin receptor gene (neuronal insulin receptor knock-out mice) exhibit impaired energy disposal and fuel metabolism [22]. In this study we investigated the impact of brain IGFBP-6 overexpression on the regulation of energy homeostasis.

\section{Materials and methods}

Animals and diet Studies were performed with two lines (16 and 17) of 3-month-old male IGFBP-6 transgenic mice bred in our laboratory [18] or with B6/CBA wild-type mice (Charles River, Grenoble, France). Mice were fed a high-fat diet for up to 3 months (33\% lard, 7\% corn oil, $6 \%$ glucides, $30 \%$ proteins; $22,100 \mathrm{~kJ} / \mathrm{kg}$; UAR, Villemoisson sur Orge, France). Control IGFBP-6 transgenic mice or B6/ CBA wild-type mice were fed standard chow pellets $(4 \%$ corn oil, $60 \%$ glucides, $20 \%$ proteins; $12,000 \mathrm{~kJ} / \mathrm{kg}$; UAR). Throughout the study period, the mice had free access to food and water. Food intake was measured daily for 2 weeks. The mean quantity was calculated and related to the weight of the mice. Animals were weighed weekly, and blood samples collected from the caudal vessels were placed in a heparinised tube for the measurement of plasma leptin, insulin, glucose, triglyceride and NEFA concentrations. Animal usage was in compliance with the Animal Care Committee of the University of Paris 7 and the guidelines of the French Physiological Society.

Glucose- or insulin-tolerance tests Glucose- and insulintolerance tests were carried out in the transgenic and wildtype mice before and after the 3 months of a high-fat or regular diet. Intraperitoneal glucose-tolerance tests were performed after a 4-h fast. Briefly, a single dose of glucose was injected intraperitoneally ( $1 \mathrm{~g} / \mathrm{kg}$ body weight). Blood samples were drawn from caudal vessels at $0,5,10,30$ and $60 \mathrm{~min}$ following glucose injection. Glycaemia was immediately measured using a glucose analyser (Roche Diagnostics, Meylan, France). Plasma was then removed and stored at $-20^{\circ} \mathrm{C}$ for radioimmunoassay of insulin.

For insulin-tolerance tests, a single dose of insulin $(0.75$ U/kg body weight; Actrapid Novo, Copenhagen, Denmark) was injected intraperitoneally and, as in the glucose-tolerance tests, glycaemia was measured from caudal vessels at $0,5,10,30$ and 60 min following insulin injection.

Energy metabolism Energy metabolism was measured in wild-type $(n=5)$, line $16(n=4)$ and line $17(n=5)$ mice by means of an indirect calorimeter (Bioseb, Chaville, France) that continuously measures spontaneous activity. This device allows discrimination between total energy expenditure and energy expended through activity (AddenFi prototype, AddenFi, Paris, France) [23]. The device was kept in a room in which an artificial light-dark cycle was maintained, with lights on from 06.00 to 18.00 hours. Mice under controlled feeding conditions were housed in the calorimeter at 10.00 hours and given free access to water but no access to food. At 18.00 hours, a 1.1-g pellet of highfat food was introduced into the calorimeter and the measurements were taken until the next morning at 09.00 hours. Data acquisition was performed at $1 \mathrm{~Hz}$ for oxygen consumption and carbon dioxide production, and at $100 \mathrm{~Hz}$ for activity. Data were averaged and stored at 10-s intervals.

At the end of the study, the stored data were further averaged at 30-min intervals and converted into ASCII format for group averaging and statistical analysis.

Analytical methods Radioimmunoassay kits were used to measure plasma leptin (Linco Research, Palo Alto, CA, USA) and insulin (DiaSorin, Les Ullis, France) concentrations. Plasma NEFA and triglyceride concentrations were measured using enzymatic assays (the NEFA-C test from Wako chemicals [Marburg, Germany] and the GPO kit from Sigma [Draveil, France], respectively).

RNA isolation and analysis by one-step RT-PCR or lightcycler quantitative RT-PCR Total RNA was extracted from frozen tissue using TriZol reagent according to the manufacturer's instructions (Invitrogen, Plaisir, France).

A one-step RT-PCR kit (Invitrogen) was used for the analyses of transgene expression (h-IGFBP-6) and glyceraldehyde-3-phosphate dehydrogenase (GAPDH) using 500 ng of total RNA. The human IGFBP-6 forward primer was 5'-CACTGCCCGCCCACAGGATGTG-3' and the reverse primer was 5'-ACAATTGGGCACGTAGAGTGTT-3'. GAPDH expression was used as a positive control (forward primer 5'-ACCACAGTCCATGCCATCAC-3' and reverse primer 5'-TCCACCACCCTGTTGCTGTA-3' [GenBank Accession: G65758]).

For $U C P-1$ and -3 , total RNA $(1 \mu \mathrm{g})$ was reverse transcribed using random hexamer primers $\left(\mathrm{dp}(\mathrm{N})_{6}\right.$; Amersham Biosciences, Saclay, France), the Revertaid H minus M-MuLV reverse transcriptase (Fermentas, Newark, NJ, USA) and RNase inhibitor (RNasin Ribonuclease Inhibitor, $40 \mathrm{U} / \mu \mathrm{l}$; Promega, Madison, WI, USA). The cDNA was amplified using QuantiTect SYBER Grenn PCR Master Mix (Qiagen, Courtaboeuf, France). The cycling conditions were $15 \mathrm{~min}$ polymerase activation at $95^{\circ} \mathrm{C}$ and 50 cycles at $95^{\circ} \mathrm{C}$ for $15 \mathrm{~s}, 60^{\circ} \mathrm{C}$ for $20 \mathrm{~s}$ and $72^{\circ} \mathrm{C}$ for $10 \mathrm{~s}$. LightCycler Software (version 3.5; Roche) results were imported into Microsoft Excel for further analysis. These values were normalised to the ribosomal protein S26 RNA levels. All primers were designed with a modified minimum of $150 \mathrm{bp}$ and a maximum of $250 \mathrm{bp}$ for the amplicon length.

Mouse UCP-1 forward primer was 5'-TCTTCAGGGC TGAGTCCTTT-3' and reverse primer was 5'-GGCTGA 
GAAGATCTTGACCC-3. For $U C P-3$, the forward primer was 5'-CAACGGTTGTGAAGTTCCTG-3' and the reverse primer was 5'-CTCTGTGCGCACCATAGTCA-3', and for S26 the forward primer was 5'-AAGTTTGT CATTCGGAACATTG-3' and the reverse primer was 5'-GATCGATTCCTAACAACCTTGC-3'.

Statistical analysis All data are presented as means \pm SEM. Student's $t$-test and, in the case of heterogeneity of variance, the Mann-Whitney test were used to compare means between the two groups. For multiple comparisons of means, ANOVA was used, followed by the NewmanKeuls test or the Kruskal-Wallis test as appropriate. A $p$ value below 0.05 was considered significant.

\section{Results}

Analysis of h-IGFBP-6 transgenic mice Human IGFBP-6 transgene expression was found in the whole brain and also in the hypothalamus of the two transgenic mice lines tested (lines 16 and 17), but not in the wild-type mice (Fig. 1a). No IGFBP-6 transcript was detectable in the brown adipose tissue (BAT), the white adipose tissue, the muscle and the pancreas (Fig. 1b). In the liver of the two transgenic mouse lines, a small amount of transcript was detected. This result is consistent with the previous detection of GFAP expression in the hepatic stellate cell [24] (Fig. 1b).

a

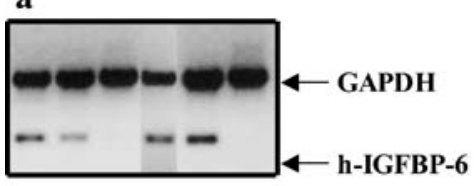

1716 WT 1716 WT

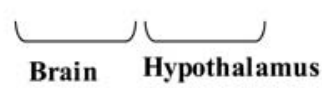

b

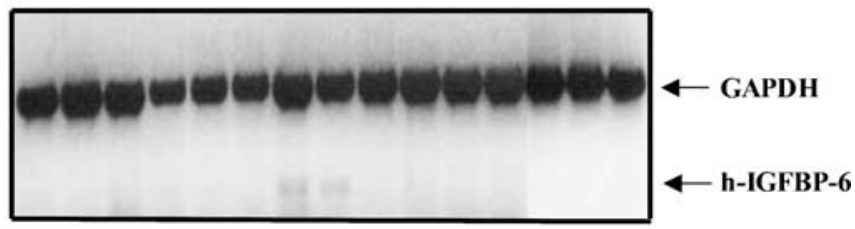

1716 WT17 16 WT17 16 WT 17 16 WT17 16 WT

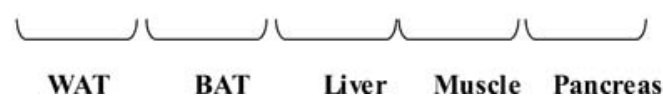

Fig. 1 h-IGFBP-6 mRNA expression. a Reverse transcription PCR was performed for h-IGFBP-6 and GAPDH from $500 \mathrm{ng}$ of total RNA extracted from the brain or the hypothalamus of homozygous transgenic line 16 (16) and line 17 (17) mice or from wild-type mice $(W T)$. GAPDH fragments were used as RT-PCR loading controls. b h-IGFBP-6 and GAPDH were amplified from $500 \mathrm{ng}$ total RNA extracted from white adipose tissue (WAT), brown adipose tissue $(B A T)$ or the liver, muscle or pancreas
Body weight increase and food intake On the high-fat diet, male transgenic mice developed obesity (Fig. 2a). On the control diet, there was no difference between transgenic (lines 16 and 17) and wild-type mice (Fig. 2b). Food intake was similar in the two groups (Fig. 2c).
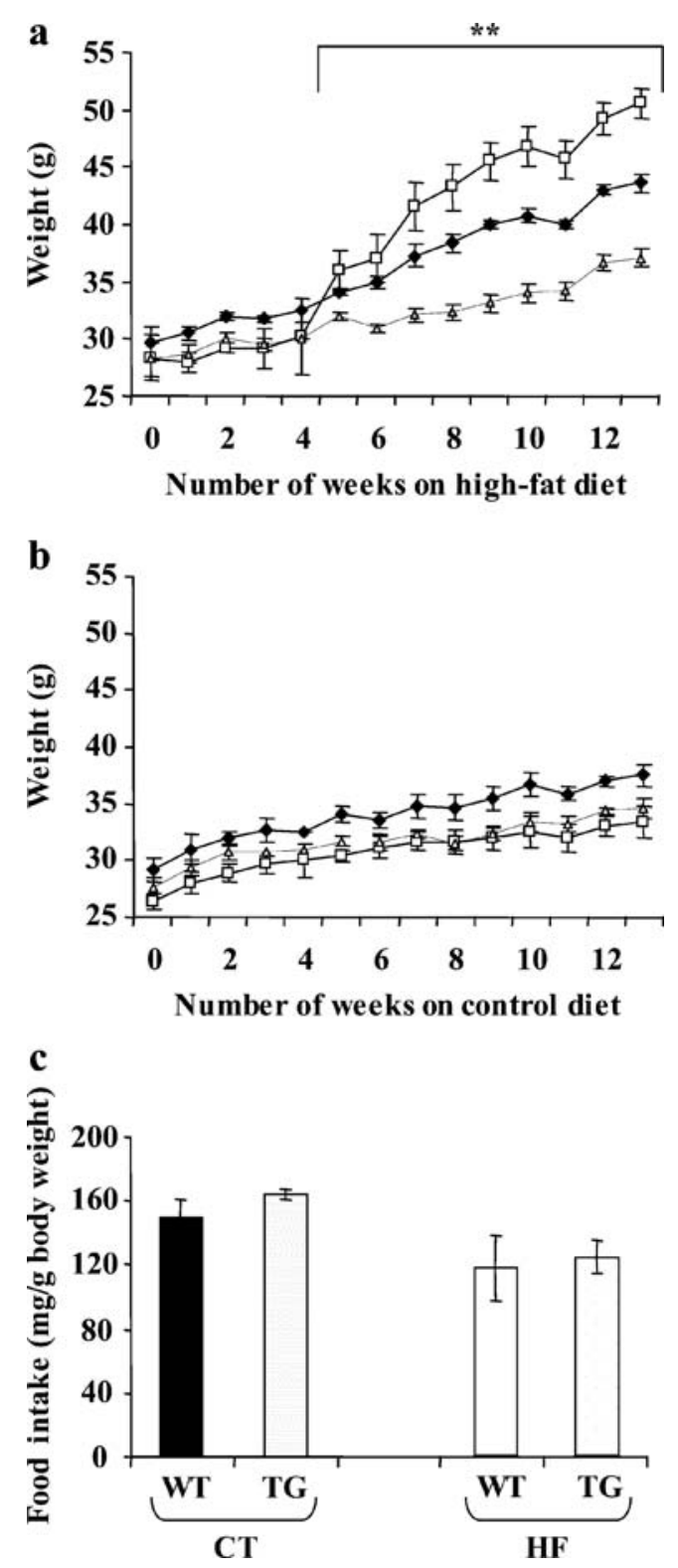

Fig. 2 Body weight of h-IGFBP-6 mice and wild-type mice. a Three-month-old males from the homozygous h-IGFBP-6 transgenic-mice line 16 (solid squares) and line 17 (open squares) or from wild-type mice (solid triangles) were fed a high-fat diet for up to 3 months. ** $p<0.001$ vs wild-type mice. Data represent the means \pm SEM of at least eight animals. b Three-month-old males from IGFBP-6 transgenic mice line 16 (solid squares) and line 17 (open squares) or from wild-type mice (solid triangles) were fed a control diet for up to 3 months. Data represent the means \pm SEM of at least eight animals, and no significant variation was observed during the 3-month period. c Food intake was weighed daily for 2 weeks. The mean value was calculated and related to the weight of mice. Data represent the means \pm SEM of at least eight animals. $C T$ Control diet; $H F$ high-fat diet; $T G$ transgenic; $W T$ wild-type 
Plasma parameters On the high-fat diet, h-IGFBP-6 transgenic mice were both hyperleptinaemic and hyperinsulinaemic, with a more pronounced phenotype for line 17 (Table 1). However, on the control diet, mild hyperleptinaemia, hyperinsulinaemia and hyperglycaemia were also observed in the plasma of h-IGFBP- 6 transgenic mice as compared with control mice (Table 1). In addition, after 4 $\mathrm{h}$ of fasting, plasma glucose remained significantly higher in transgenic mice on a high-fat diet compared with wildtype mice on a high-fat diet. Plasma NEFA concentrations remained unchanged in the different groups irrespective of diet (Table 1).

Glycaemia during intraperitoneal glucose- and insulintolerance tests During intraperitoneal glucose-tolerance tests, glycaemia was higher in transgenic mice than in wild-type mice fed a control (Fig. 3b) or high-fat (Fig. 3a) diet. One hour after glucose loading, glycaemia was not back to its basal value in transgenic mice (Fig. 3a, b).

In response to an insulin injection, the decrease in glycaemia was less marked in transgenic mice fed a control diet than in wild-type mice (Fig. 4), suggesting insulin resistance. Moreover, in transgenic mice, glycaemia was back to its basal value $60 \mathrm{~min}$ after insulin injection, whereas it remained lower in wild-type mice (Fig. 4). As depicted in Fig. 4a, high-fat feeding reinforced insulin resistance in transgenic mice as compared with the wild-type group. It is worth noting that line 17 seemed to be more insulin resistant than line 16 . This transgenic mouse line also developed a stronger diet-induced obesity phenotype (Fig. 2) associated with increased expression in the brain (Fig. 1).

Uncoupling proteins In the BAT of both control-diet transgenic mouse lines (16 and 17), uncoupling protein (UCP)-1 expression was significantly decreased compared with that of their wild-type littermates (Fig. 5a). The highfat diet induced an increase of UCP-1 expression in the BAT of both transgenic and wild-type mice (Fig. 5a), but it was still underexpressed in transgenic mice compared with in wild-type mice. On the high-fat diet, UCP-3 expression was increased approximately three-fold in the soleus of transgenic mice (Fig. 5b).

Components of energy metabolism Total energy expenditure was not different among wild-type, line 16 and line 17 mice throughout the study (Fig. 6). The respiratory quo-
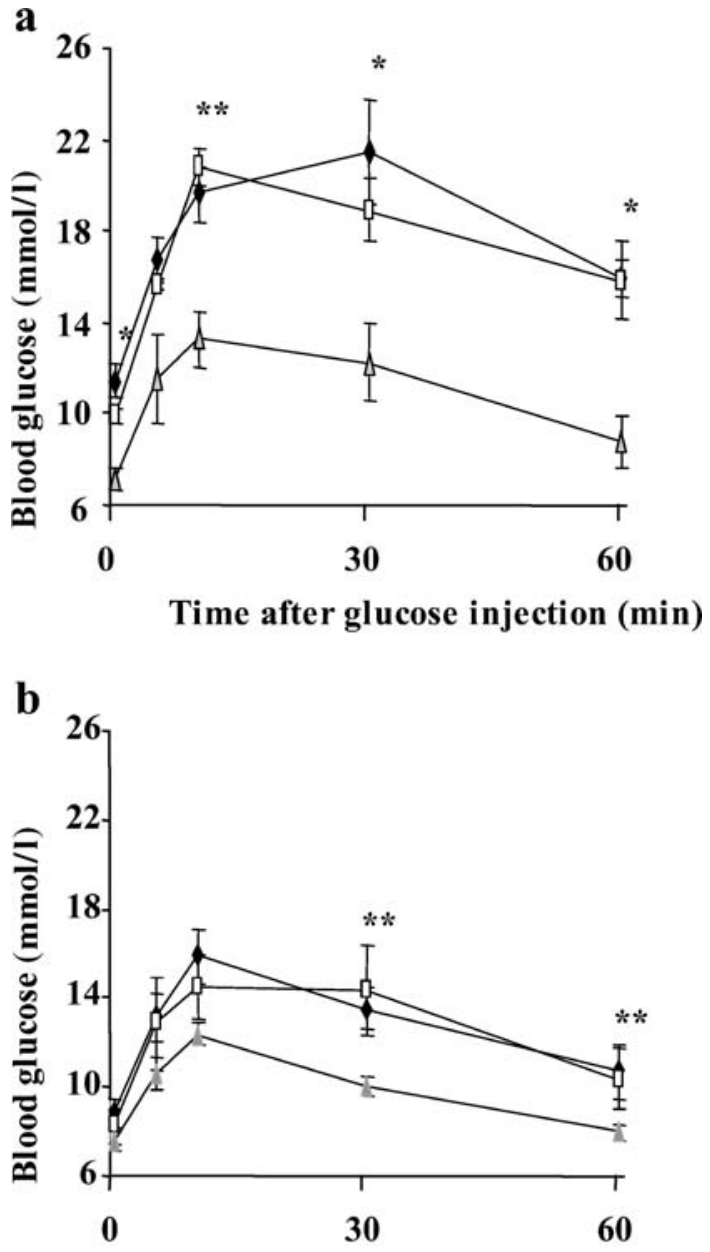

Time after glucose injection ( $\mathrm{min})$

Fig. 3 Intraperitoneal glucose tolerance tests (IPGTTs). a Glycaemia during IPGTT ( $1 \mathrm{~g} / \mathrm{kg}$-body weight) performed after a 4-h fast following 3 months of a high-fat diet. Blood samples were collected from the tails of homozygous line 16 (solid squares), homozygous line 17 (open squares) or wild-type (open triangles) mice. b IPGTT performed after a 4-h fast following 3 months of a control diet. Results are from homozygous line 16 (solid squares), homozygous line 17 (open squares) and wild-type (open triangles) mice. Student's $t$-test was used for statistical analysis $* * p<0.0001$ and $* p<0.001$ vs wild-type. Data represent the means \pm SEM of at least eight animals

tient was similar between groups in the post-absorptive state (i.e. before the meal and by the end of the studies),
Table 1 Plasma parameters of 6-month-old animals after 3 months of a high-fat or control diet

Leptin and insulin dosages were carried out using a radioimmunoassay kit. Glucose concentrations were analysed using a glucose analyser. Triglycerides (TGs) and NEFAs were measured using enzymatic assays ${ }^{\mathrm{a}} p<0.001$ vs wild-type

\begin{tabular}{lcllll}
\hline & $\begin{array}{l}\text { Leptin } \\
(\mathrm{ng} / \mathrm{ml})\end{array}$ & $\begin{array}{l}\text { Insulin } \\
(\mathrm{ng} / \mathrm{ml})\end{array}$ & $\begin{array}{l}\text { Glucose } \\
(\mathrm{mmol} / \mathrm{l})\end{array}$ & $\begin{array}{l}\text { TGs } \\
(\mathrm{mg} / \mathrm{l})\end{array}$ & $\begin{array}{l}\text { NEFAs } \\
(\mu \mathrm{mol} / \mathrm{l})\end{array}$ \\
\hline $\begin{array}{l}\text { High-fat diet } \\
\text { Line 16 }\end{array}$ & $49 \pm 8^{\mathrm{a}}$ & $2.9 \pm 0.3^{\mathrm{a}}$ & $11.4 \pm 0.7^{\mathrm{a}}$ & $16.7 \pm 1.6^{\mathrm{a}}$ & $704 \pm 54$ \\
Line 17 & $78 \pm 3^{\mathrm{a}}$ & $9.0 \pm 1.5^{\mathrm{a}}$ & $9.9 \pm 0.3^{\mathrm{a}}$ & $23.5 \pm 4.1$ & $725 \pm 153$ \\
Wild-type & $14 \pm 2$ & $1.1 \pm 0.1$ & $7.8 \pm 0.7$ & $27.6 \pm 4.3$ & $775 \pm 42$ \\
Control diet & & & & & \\
Line 16 & $10.9 \pm 2.3^{\mathrm{a}}$ & $1.89 \pm 0.43^{\mathrm{a}}$ & $8.8 \pm 0.7^{\mathrm{a}}$ & $23.0 \pm 3.8^{\mathrm{a}}$ & $932 \pm 85$ \\
Line 17 & $10.3 \pm 2.6^{\mathrm{a}}$ & $1.49 \pm 0.30^{\mathrm{a}}$ & $8.2 \pm 0.6^{\mathrm{a}}$ & $14.6 \pm 1.6^{\mathrm{a}}$ & $943 \pm 89$ \\
Wild-type & $6.0 \pm 0.6$ & $0.72 \pm 0.19$ & $7.5 \pm 0.4$ & $36.9 \pm 6.4$ & $897 \pm 58$ \\
\hline
\end{tabular}




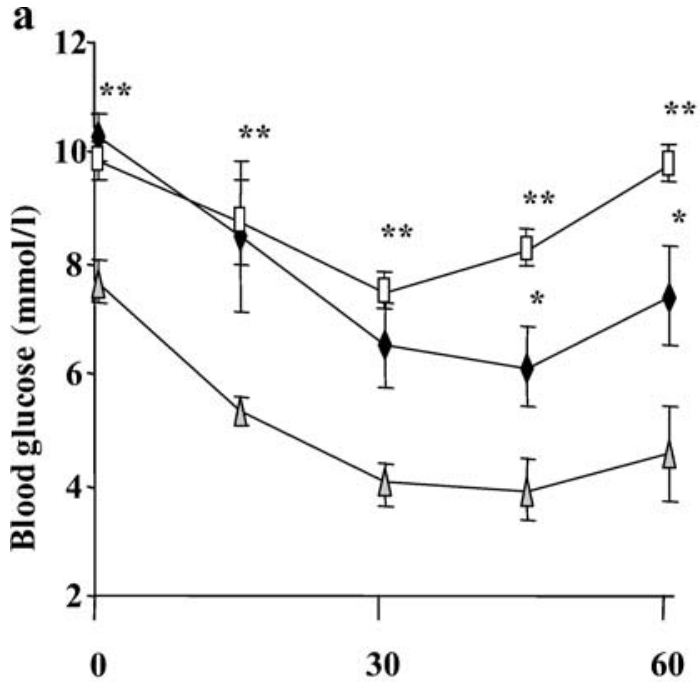

Time after insulin injection (min)

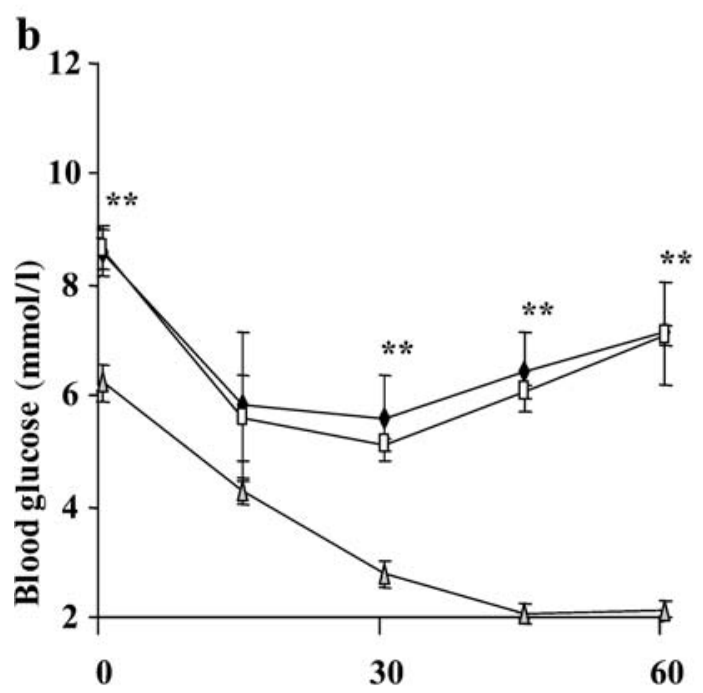

Time after insulin injection (min)

Fig. 4 Intraperitoneal insulin tolerance tests (IPITTs). a Glycaemia during IPITT $(0.75 \mathrm{U} / \mathrm{kg}$ body weight $)$ performed after a 4-h fast following 3 months of a high-fat diet. Results are from homozygous line 16 (solid squares), homozygous line 17 (open squares) and wild-type (open triangles) mice. b IPITT performed after a 4-h fast following 3 months of a control diet. Results are from homozygous line 16 (solid squares), homozygous line 17 (open squares) and wild-type (open triangles) mice. Student's $t$-test was used for statistical analysis. ${ }^{* *} p<0.0001$. Data represent the means \pm SEM of at least eight animals

but the respiratory quotient response to feeding was of lower amplitude and longer duration in line 17 mice than in control and line 16 mice (Fig. 7). Spontaneous activity was lower in line 16 mice than in control and line 17 mice. This was related to a lower activity during the postprandial period (Fig. 8). Analysis of the relationship between the changes in total metabolic rate and activity showed strong correlations in all groups $(0.86<r<0.95)$, indicating that the changes in $\mathrm{VO}_{2}$ and $\mathrm{VCO}_{2}$ closely followed the changes in spontaneous activity in all groups
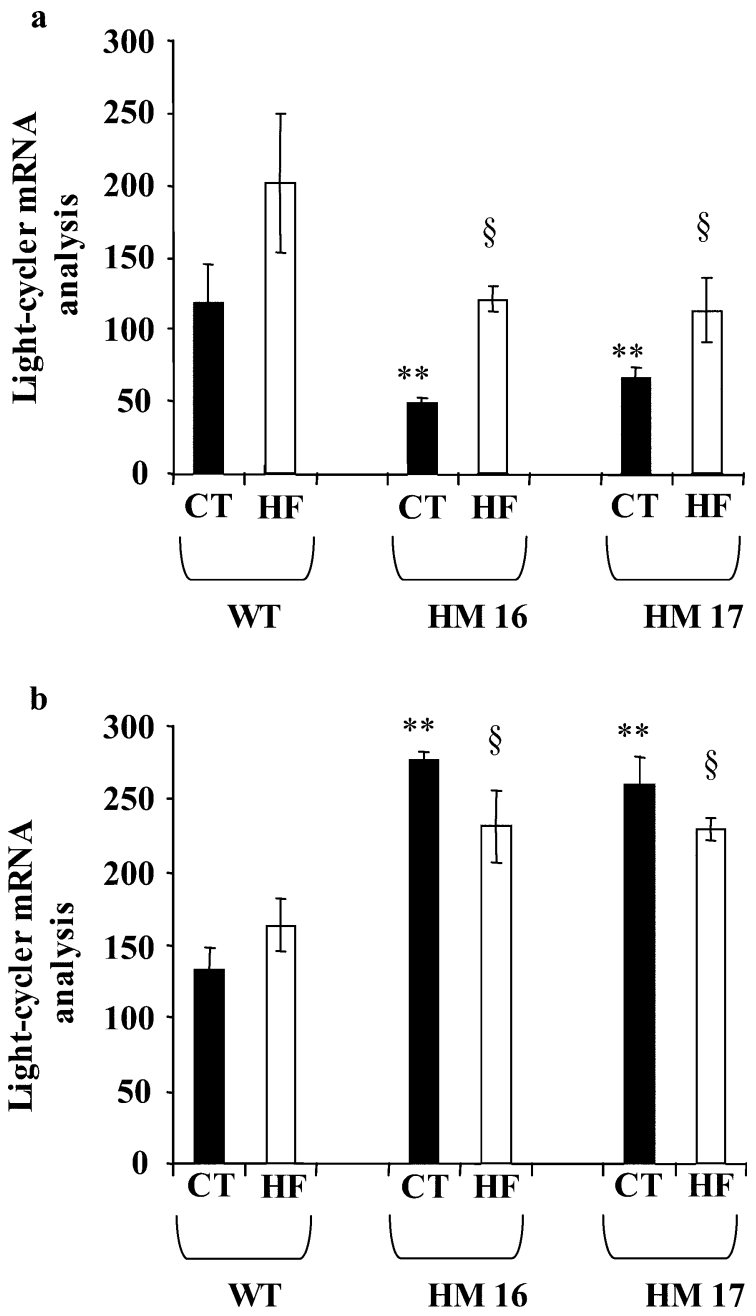

Fig. 5 UCP expression. a UCP-1 gene expression in brown adipose tissue. UCP-1 fragment was amplified from mouse cDNA reverse transcript from $1 \mu \mathrm{g}$ of total RNA extracted from brown adipose tissue (BAT) of homozygous transgenic line 16 (HM 16), line 17 (HM 17 ) or wild-type (WT) mice. Analyses were carried out in animals on a control diet $(C T)$ or high-fat diet $(H F)$. Three light-cycler experiments were performed to quantify UCP expression using BAT from two different mice in each experiment. CT diet: $* * p<0.001$; HF diet:

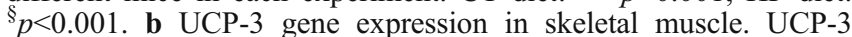
fragment was amplified from mouse cDNA reverse transcript from 1 $\mu \mathrm{g}$ of total RNA extracted from soleus muscle. Analyses were carried out as described above. CT diet: ${ }^{* *} p<0.001$; HF diet: ${ }^{\S} p<0.001$

(Fig. 9). Given that the slopes of the correlations reveal the metabolic cost of activity, it appears that the increases in oxygen consumption and carbon dioxide production per unit of activity were significantly lower in line 17 than in wild-type and line 16 mice (Table 2). The respiratory quotient associated with activity $\left(\delta \mathrm{VCO}_{2} / \delta \mathrm{VO}_{2}\right)$ was the same in the three groups, however, indicating that there was no difference in the glucose: lipid ratio used to fuel muscular efforts (Fig. 9). Computation of resting energy expenditure by subtracting the metabolic cost of activity from total energy expenditure showed that resting metabolic rate decreased during activity in control mice, a phenomenon that was less pronounced in line 16 mice and totally absent in line 17 mice (Fig. 9). 

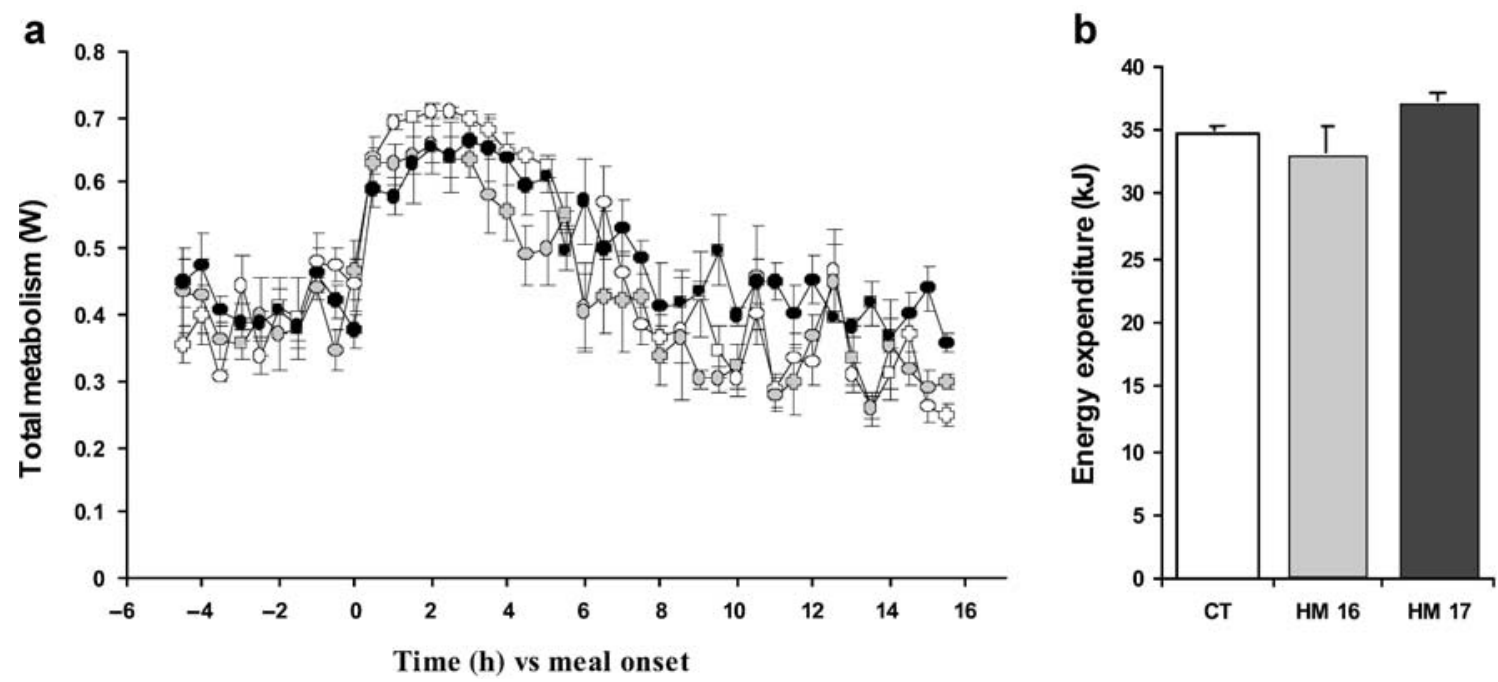

Fig. 6 Total metabolic rate averaged at 30-min intervals throughout the study (a), and average energy expenditure throughout the study (b). The 1.1-g test meal of the usual high-fat food was given at time

\section{Discussion}

This study revealed that IGFBP-6 overexpression in the brain leads to mild hyperleptinaemia, hyperinsulinaemia, insulin resistance, high-fat-diet-induced obesity and several alterations in the components of energy metabolism.

Obesity reflects a dysregulation in energy balance and it is known that energy intake and expenditure are monitored by the hypothalamus, which releases orexigenic or anorexigenic neuropeptides [25]. In our study, there was no significant change in neuropeptide $\mathrm{Y}$ or cocaine- and amphetamine-regulated transcript gene expression in hIGFBP-6 transgenic mice (data not shown). Moreover, transgenic mice displayed hyperleptinaemia without any change in food intake. Interestingly, a study has shown

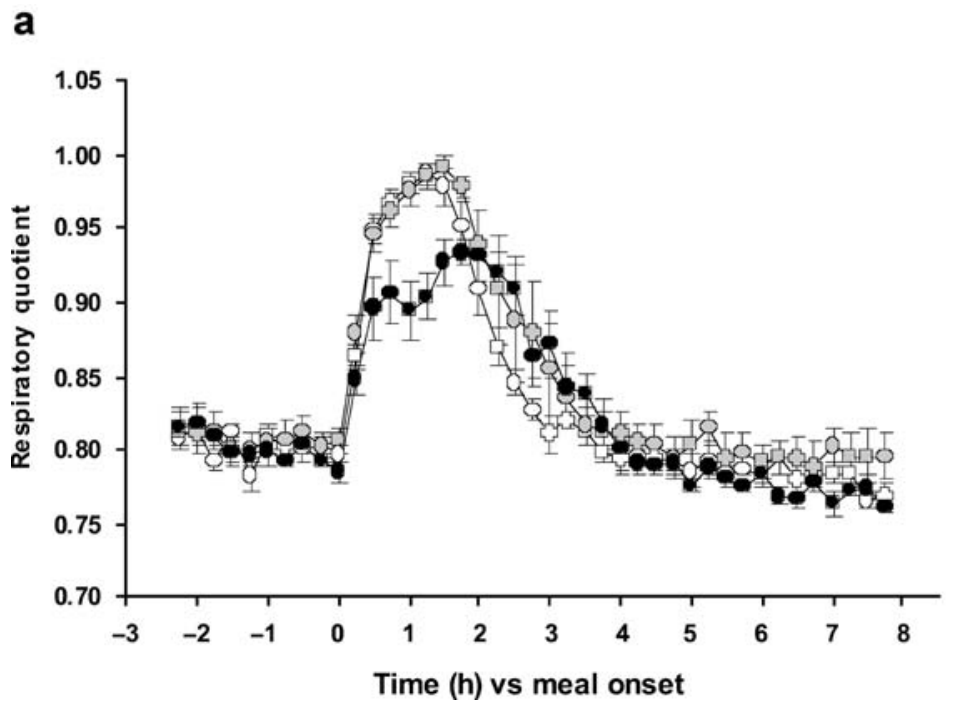

0 . Results are from homozygous line 16 (open circles), homozygous line 17 (solid squares) and control (open circles) mice. CT Control; $H M$ homozygous

that intracerebroventricular infusion of insulin, but not of IGF-I, decreased food intake, whereas in the brain both can influence the concentration of insulin in the blood [26].

In our model, diet-induced obesity was associated with an increase in plasma leptin levels, mild insulin resistance and elevated insulin and glucose levels, suggesting that IGFBP/IGF might play a central role in the regulation of body weight and glucose homeostasis. Because of structural homologies between IGF and insulin, IGF can bind to the insulin receptor. IGF activity could also be mediated by the insulin receptor and, interestingly, similar phenotypes were observed in neuronal insulin receptor knock-out mice, which have a neuron-specific disruption of the insulin receptor $(I R)$ gene [22]. In addition, transgenic mice lacking IRS-2 developed obesity despite elevated levels of leptin [19]. Taken together, these data suggest that insulin and

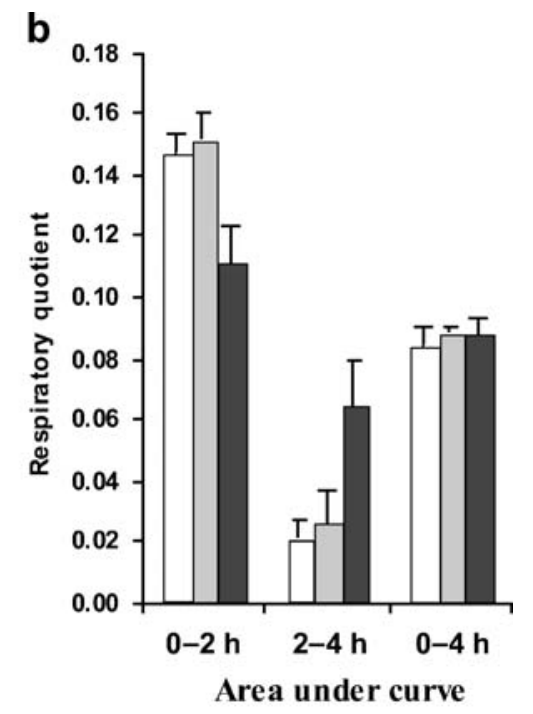

Fig. 7 Respiratory quotient averaged at 30-min intervals throughout the study (a), and average value throughout the study (b). The 1.1-g test meal of the usual high-fat food was given at time 0 . Results are

from homozygous line 16 (grey circles, grey bar), homozygous line 17 (solid circles, black bar) and control (open circles, white bar) mice 
a

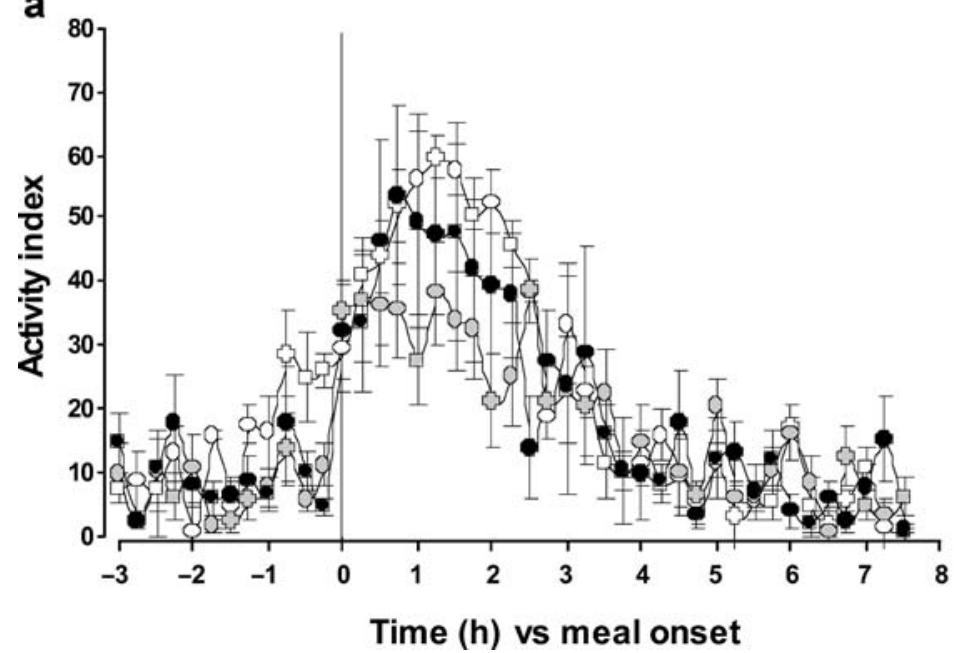

b

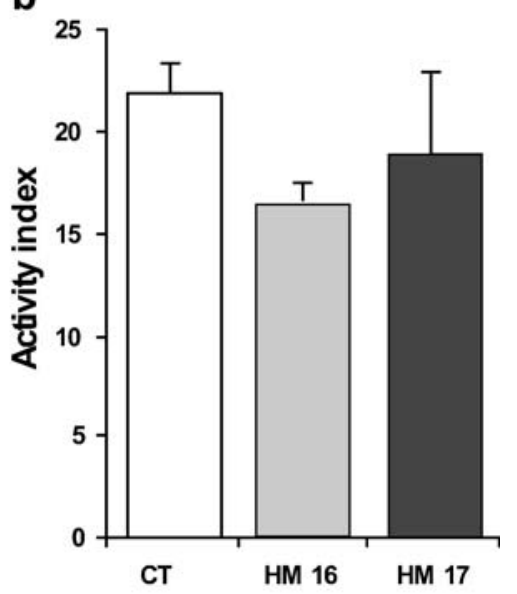

Fig. 8 Spontaneous motor activity averaged at 30-min intervals throughout the study (a), and average value throughout the study (b). The 1.1-g test meal of the usual high-fat food was given at time

IGFs are important brain regulators for the control of body weight and glucose homeostasis. Furthermore, insulin, IGF-I, IGF-II and their receptors are expressed in hypothalamic regions implicated in adiposity signalling and regulation of food intake in humans and rodents [27].

Obesity could also be related to a decrease in energy expenditure, as h-IGFBP-6 transgenic mice developed dietinduced obesity without hyperphagia. Consequently, we measured mice activity, expression of UCPs and energy metabolism. UCP-1 mRNA expression in transgenic mice was reduced by about $50 \%$. Thus, lower UCP-1 gene expression in h-IGFBP-6 mouse BAT could lead to obesity induced by a high-fat diet because of a diminished energy expenditure or a defective thermogenic response to cold or to feeding. Nevertheless, in both transgenic and wild-type mice, UCP-1 mRNA level was doubled in BAT in response to a high-fat diet, suggesting that mechanisms leading to UCP-1 up-regulation were functional in h-IGFBP-6 transgenic mice $[28,29]$. We observed, however, a three-fold increase in UCP-3 expression in the skeletal muscle of IGFBP-6 transgenic mice. This increase could be, at least in part, a way for these transgenic mice to compensate for the lack of UCP-1. The suggestion that UCP-3 can uncouple respiration in muscle mitochondria [30] is worth noting.

As these animals presented alterations in cerebellum development, we looked at whether energy expenditure could be related to reduced locomotricity. Measurement of the various components of energy expenditure showed that total daily energy expenditure was not decreased in IGF BP-6 transgenic mice despite a slight decrease in spontaneous activity in the line 16 model. A lack of alteration in activity in line 17 mice and the rather weak effect observed in line 16 mice indicate that the effects on activity of the reduced size of the cerebellum led to smaller effects on activity than could be anticipated. In addition, respiratory quotient, that is the ratio of glucose: lipid oxidation at the whole-body level, was the same in all groups in the post-
0 . Results are from homozygous line 16 (grey circles), homozygous line 17 (solid circles) and control (open circles) mice. CT Control; $H M$ homozygous

absorptive state. The amplitude of the discrepancy leading to obesity in the long term could obviously be too small to be quantified by comparing food intake and energy expenditure data, because the uncertainties of both kinds of measurement are far stronger than the very tiny discrepancies leading to obesity in the long term. The calorimetry data revealed, however, that a clear defect occurred in line 17 mice in the post-prandial respiratory quotient response. This defect was characterised by a post-prandial respiratory quotient increase of lower amplitude and longer duration, which suggests a defect in the post-prandial utilisation of glucose and lipids. Such a phenomenon was already suggested by the glucose- and insulin-tolerance tests.

The overall similarity in total energy expenditure between the three groups also hides a defective regulation in energy metabolism in the fact that the components of energy expenditure underlying total energy expenditure, i.e. resting energy expenditure and the energetic cost of activity, were different between groups and were particularly altered in line 17 mice. This could suggest a defect in sympathetic tone activity, as these mice also displayed hypogonadism [18]. Resting energy expenditure is the sum of basal energy expenditure, meal-induced thermogenesis and non-shivering thermogenesis, while energy expended with activity is the intensity of the activity multiplied by its metabolic cost. The fact that in control mice, resting metabolism decreased during activity was a normal and expected response to the extra heat generated by muscular work, and assuming that non-shivering thermogenesis works normally in these mice, was probably the result of a prompt inhibition of UCP-1-mediated heat production in BAT. The observation that line 17 mice, and to a lesser extent line 16 mice, did not respond in the same way as control mice suggests that the process responsible for heat generation in these transgenic mice was not the same as the process in control mice. The fact that UCP-1 activity was $50 \%$ lower in these transgenic mice may be the reason that cold-induced stimulation of UCP-1 activity could not 
Fig. 9 Changes in total metabolic rate (TMR, open circles), resting metabolic rate (RMR, open squares) and activity (solid line) averaged at 30-min intervals throughout the study in control (a), line 16 (b) (TMR grey circles, RMR grey squares) and line 17 (c) (TMR grey circles, RMR grey squares) mice. The horizontal dashed line shows the RMR of a C57B16 mouse kept at thermoneutrality $\left(32.5^{\circ} \mathrm{C}\right.$; value taken from another study). The meal was given at time 0
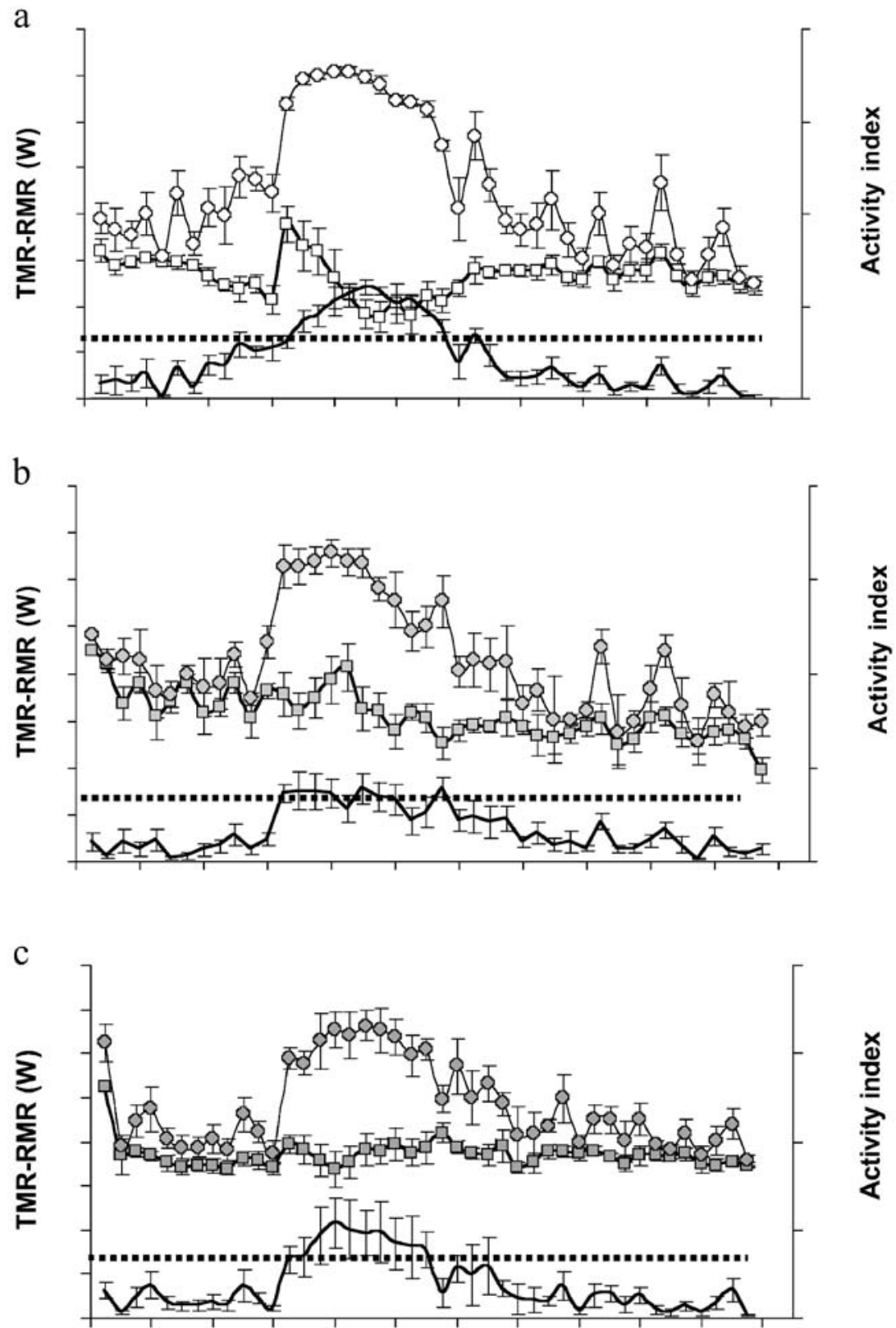

Table 2 Changes in oxygen consumption $\left(\delta \mathrm{VO}_{2}\right)$ and carbon dioxide production $\left(\delta \mathrm{VCO}_{2}\right)$ per unit of activity

\begin{tabular}{llll}
\hline & Wild-type mice & Line 16 mice & Line 17 mice \\
\hline $\begin{array}{c}\delta \mathrm{VO}_{2} / \text { unit } \\
\text { activity }\end{array}$ & $0.095 \pm 0.009$ & $0.075 \pm 0.005^{\mathrm{a}}$ & $0.057 \pm 0.003^{\mathrm{a}}$ \\
$\begin{array}{c}\delta \mathrm{VCO}_{2} / \text { unit } \\
\text { of activity }\end{array}$ & $0.086 \pm 0.008$ & $0.069 \pm 0.003^{\mathrm{a}}$ & $0.054 \pm 0.004^{\mathrm{a}}$ \\
$\begin{array}{c}\text { RQ of } \\
\text { activity }\end{array}$ & $0.909 \pm 0.02$ & $0.926 \pm 0.022^{\mathrm{a}}$ & $0.948 \pm 0.013^{\mathrm{a}}$ \\
\end{tabular}

The respiratory quotient (RQ) of activity is the ratio of oxygen consumption to carbon dioxide production specifically associated with locomotor activity ${ }_{p}<0.001$ vs wild-type produce enough heat in the transgenic mice, and thus that another mechanism had to be recruited to complete nonshivering thermogenesis. The increased UCP-3 activity observed in the transgenic mice may be part of this complementary mechanism. As UCP-3 has been reported to improve GLUT4 translocation and glucose transport by the muscles [30], this could be a way for these insulinresistant mice to improve glucose uptake and utilisation by the muscles. This could be suggested from the present data as a result of the slightly higher respiratory quotient associated with muscular contraction in the transgenic mice (Table 2).

To summarise, this study revealed that IGFBP-6 overexpression in the brain leads to mild hyperleptinaemia, 
hyperinsulinaemia, insulin resistance obesity induced by a high-fat diet, which is partly related to a decrease in UCP-1 expression in BAT, associated with several alterations in the components of energy metabolism. In particular, line 17 mice, which were the most sensitive to dietary induced obesity, exhibited signs of insulin resistance, and lines 16 and 17 exhibited alterations in the processes responsible for non-shivering thermogenesis. Taken together, these results suggest that the brain IGF system has an impact on the regulation of energy homeostasis.

Acknowledgements This work was supported by the National Institute of Health and Medical Research (INSERM, University of Paris, France) and the St-Antoine Medical Faculty (University of Paris, France). We thank P. Casanova for animal maintenance and L. Clement, K. A. Kim and C. Cruciani-Guglielmacci for their technical help.

\section{References}

1. Baxter RC (2000) Insulin-like growth factor (IGF)-binding proteins: interactions with IGFs and intrinsic bioactivities. Am J Physiol Endocrinol Metab 278:E967-E976

2. Clemmons DR (1997) Insulin-like growth factor binding proteins and their role in controlling IGF actions. Cytokine Growth Factor Rev 8:45-62

3. Shimasaki S, Ling N (1991) Identification and molecular characterization of insulin-like growth factor binding proteins (IGFBP$1,-2,-3,-4,-5$ and -6$)$. Prog Growth Factor Res 3: 243-266

4. Firth SM, Baxter RC (2002) Cellular actions of the insulin-like growth factor binding proteins. Endocr Rev 23:824-854

5. Hwa V, Oh Y, Rosenfeld RG (1999) The insulin-like growth factor-binding protein (IGFBP) superfamily. Endocr Rev 20:761-787

6. Miyake H, Nelson C, Rennie PS, Gleave ME (2000) Overexpression of insulin-like growth factor binding protein-5 helps accelerate progression to androgen-independence in the human prostate LNCaP tumor model through activation of phosphatidylinositol 3'-kinase pathway. Endocrinology 141:2257-2265

7. Grellier P, De Galle B, Babajko S (1998) Expression of insulinlike growth factor-binding protein 6 complementary DNA alters neuroblastoma cell growth. Cancer Res 58:1670-1676

8. Bach LA (1999) Insulin-like growth factor binding protein-6: the 'forgotten' binding protein? Horm Metab Res 31:226-234

9. D'Ercole AJ, Ye P, Calikoglu AS, Gutierrez-Ospina G (1996) The role of the insulin-like growth factors in the central nervous system. Mol Neurobiol 13:227-255

10. D'Ercole AJ, Ye P, O'Kusky JR (2002) Mutant mouse models of insulin-like growth factor actions in the central nervous system. Neuropeptides 36:209-220

11. Werther GA, Russo V, Baker N, Butler G (1998) The role of the insulin-like growth factor system in the developing brain. Horm Res 49(Suppl 1):37-40

12. Ayer-le Lievre C, Stahlbom PA, Sara VR (1991) Expression of IGF-I and -II mRNA in the brain and craniofacial region of the rat fetus. Development 111:105-115
13. Rotwein P, Burgess SK, Milbrandt JD, Krause JE (1988) Differential expression of insulin-like growth factor genes in rat central nervous system. Proc Natl Acad Sci U S A 85:265-269

14. Torres-Aleman I, Pons S, Arevalo MA (1994) The insulin-like growth factor I system in the rat cerebellum: developmental regulation and role in neuronal survival and differentiation. $J$ Neurosci Res 39:117-126

15. McKelvie PA, Rosen KM, Kinney HC, Villa-Komaroff L (1992) Insulin-like growth factor II expression in the developing human brain. J Neuropathol Exp Neurol 51:464-471

16. Brenner M, Messing A (1996) GFAP transgenic mice. Methods 10:351-364

17. Galou M, Pournin S, Ensergueix D et al (1994) Normal and pathological expression of GFAP promoter elements in transgenic mice. Glia 12:281-293

18. Bienvenu G, Seurin D, Grellier P et al (2004) IGFBP-6 transgenic mice: post-natal growth, brain development and reproduction abnormalities. Endocrinology 145:2412-2420

19. Burks DJ, de Mora JF, Schubert M et al (2000) IRS-2 pathways integrate female reproduction and energy homeostasis. Nature 407:377-382

20. Withers DJ (2001) Insulin receptor substrate proteins and neuroendocrine function. Biochem Soc Trans 29:525-529

21. Carvalheira JB, Ribeiro EB, Araujo EP et al (2003) Selective impairment of insulin signalling in the hypothalamus of obese Zucker rats. Diabetologia 46:1629-1640

22. Bruning JC, Gautam D, Burks DJ et al (2000) Role of brain insulin receptor in control of body weight and reproduction. Science 289:2122-2125

23. Even P, Mokhtarian A, Pele A (1994) Practical aspects of indirect calorimetry in laboratory animals. Neurosci Biobehav Rev 18:435-447

24. Guma FCR, Mello TG, Mermelstein CS et al (2001) Intermediate filaments modulation in an in vitro model of the hepatic stellate cell activation or conversion into the lipocyte phenotype. Biochem Cell Biol 79:409-417

25. Sahu A, Dube MG, Phelps CP, Sninsky CA, Kalra PS, Kalra SP (1995) Insulin and insulin-like growth factor II suppress neuropeptide $\mathrm{Y}$ release from the nerve terminals in the paraventricular nucleus: a putative hypothalamic site for energy homeostasis. Endocrinology 136:5718-5724

26. Foster LA, Ames NK, Emery RS (1991) Food intake and serum insulin responses to intraventricular infusions of insulin and IGF-I. Physiol Behav 50:745-749

27. Baskin DG, Wilcox BJ, Figlewicz DP, Dorsa DM (1988) Insulin and insulin-like growth factors in the CNS. Trends Neurosci 11:107-111

28. Klein J, Fasshauer M, Benito M, Kahn CR (2000) Insulin and the beta3-adrenoceptor differentially regulate uncoupling protein-1 expression. Mol Endocrinol 14:764-773

29. Rohner-Jeanrenaud F (2000) Hormonal regulation of energy partitioning. Int J Obes Relat Metab Disord 24 (Suppl 2):S4-S7

30. Huppertz C, Fischer BM, Kim YB et al (2001) Uncoupling protein 3 (UCP3) stimulates glucose uptake in muscle cells through a phosphoinositide 3-kinase-dependent mechanism. J Biol Chem 276:12520-12529 